\title{
Predicting the outcome of a cognitive-behavioral group training for patients with unexplained physical symptoms: a one-year follow-up study
}

Lyonne NL Zonneveld ${ }^{1,2,3^{*}}$, Yanda R van Rood ${ }^{4}$, Cornelis G Kooiman' ${ }^{5}$, Reinier Timman', Adriaan van 't Spijker ${ }^{1}$ and Jan JV Busschbach'

\begin{abstract}
Background: Although Cognitive-Behavioral Therapy (CBT) is effective for Unexplained Physical Symptoms (UPS), some therapists in clinical practice seem to believe that CBT outcome will diminish if psychiatric comorbidity is present. The result is that patients with a psychiatric comorbidity are redirected from treatment for UPS into treatment for mental health problems. To explore whether this selection and allocation are appropriate, we explored whether CBT outcomes in UPS could be predicted by variables assessed at baseline and used in routine-practice assessments.
\end{abstract}

Methods: Patients ( $\mathrm{n}=162$ ) with UPS classified as undifferentiated somatoform disorder or chronic pain disorder were followed up until one year after they had attended a CBT group training. The time-points of the follow-up were at the end of CBT (immediate outcome), three months after CBT (short-term outcome), and one year after CBT (long-term outcome).

CBT outcome was measured using the Physical Component Summary of the SF-36, which was the primary outcome measure in the randomized controlled trial that studied effectiveness of the CBT group training. Predictors were: 1.) psychological symptoms (global severity score of SCL-90), 2.) personality-disorder characteristics (sum of DSM-IV axis II criteria confirmed), 3.) psychiatric history (past presence of DSM-IV axis I disorders), and 4.) health-related quality of life in the mental domain (mental component summary of SF-36). The effect of this predictor set was explored using hierarchical multiple regression analyses into which these predictors had been entered simultaneously, after control for: a.) pretreatment primary outcome scores, b.) age, c.) gender, d.) marital status, and e.) employment.

Results: The predictor set was significant only for short-term CBT outcome, where it explained 15\% of the variance. A better outcome was predicted by more psychological symptoms, fewer personality-disorder characteristics, the presence of a psychiatric history, and a better quality of life in the mental domain.

Conclusions: As the predictors do not seem to predict CBT outcome consistently over time, the need for selection and allocation of patients for CBT is doubtful. It seems that this would unnecessarily deprive patients of effective treatment.

Trial registration: Nederlands Trial Register, NTR1609

Keywords: Predictors, Treatment outcome, Somatoform disorders, Unexplained physical symptoms, Cognitive behavioral therapy, Assessment

\footnotetext{
* Correspondence: I.zonneveld@erasmusmc.nl

'Department of Medical Psychology and Psychotherapy, Erasmus Medical

Center, PO Box 2040, Rotterdam 3000 CA, the Netherlands

${ }^{2}$ Department of Medical Psychology, Academic Medical Center, PO Box

22660, Amsterdam 1100 DD, the Netherlands

Full list of author information is available at the end of the article
} 


\section{Background}

Although Cognitive-Behavioral Therapy (CBT) is effective for Unexplained Physical Symptoms (UPS) [1-6], some therapists in clinical practice seem to believe that it is not equally effective for all patients with UPS. Instead, they assume that outcome will be poorer in patients whose quality of life may have been affected by a psychiatric comorbidity such as depression, anxiety disorder, personality-disorder, or their psychiatric history.

Inconsistent findings have been produced by studies that investigated whether such comorbidity did indeed predict poor outcome [7-21]. Some studies showed that poor treatment outcome for UPS was predicted by concurrent depressive symptoms [9], anxiety symptoms [10], personality-disorder characteristics [11], a psychiatric history $[12,21]$ or poor health-related quality of life [12]. Other studies used the same predictors to conclude differently. Thus, for concurrent depressive symptoms, one study found that depressive symptoms predicted a better outcome [13], while others showed no influence [7,8,10,11,14-20]. For concurrent anxiety symptoms, another study found that anxiety, too, predicted a better outcome [14], while others showed no influence $[7,8,11,15-19]$. For concurrent personality disorders, two further studies found that a personality disorder did not predict outcome - though they also implied that a personality disorder might increase the drop-out rate $[8,16]$. For psychiatric history, a further study showed no influence on outcome [9]. For health-related quality of life, another study reported that poorer functioning valued by assessors and a poorer quality of life reported by patients were associated with better outcome [15]. Conclusions on whether psychiatric comorbidity predicted outcome differed not only between studies, but also within them $[12,15]$. For example, one study [12] found that depressive symptoms did not predict post-treatment outcome, but did predict better three-month follow-up outcome.

One possible reason for these inconsistent findings on predicting CBT outcome in UPS is that the impact of psychiatric comorbidity was blurred by differences in the outcome scores at baseline or in socio-demographic variables at baseline. Various studies showed that the outcome was influenced by the pretreatment score on the outcome measure $[10,12,15]$, and by sociodemographic variables such as age $[10,12,14,20]$, gender [15], marital status [13], or having paid work $[15,17]$.

To find predictors that consistently predict CBT outcome over time, we explored whether psychological symptoms, personality-disorder characteristics, psychiatric history, and health-related quality of life in the mental domain assessed at baseline predicted CBT outcome on the primary outcome measure at the end of
CBT (immediate outcome), three months after CBT (short-term outcome), and one year after CBT (longterm outcome), all after control for pretreatment scores on the outcome measure and for socio-demographic variables. In line with clinical practice, that was supported but also contradicted by a number of studies, we hypothesized that better CBT outcome would be predicted by the following: fewer psychological symptoms and personality-disorder characteristics, the absence of a psychiatric history, and a better quality of life in the mental domain.

\section{Methods \\ Design}

The data for this study came from a randomized controlled trial on the effectiveness of cognitive-behavioral group training (CBT) for patients with UPS [22]. Patients with UPS were randomized either to CBT or to a waiting list after they had completed the baseline measurement (T0). The second measurement (T1) was made directly after the training (13 weeks), or, for those on the waiting list, after the same period. The maintenance of the effect of the group training was investigated in a non-randomized one-year follow-up. To this end, patients who had been randomized to the waiting list and had waited started the training after their second measurement (T1). Patients who had attended the training directly after randomization or after the waiting period were followed-up three months after the end of treatment (T2), and again one year later (T3).

The study was approved by the Erasmus Medical Research Ethics Committee, and registered in the Dutch Trial Register (NTR 1609) [23]. A detailed description of the protocol has been published earlier in this journal [24].

\section{Participants}

Patients were recruited between February 2005 and September 2008 in general practices, in outpatient clinics at general hospitals, and by Riagg Rijnmond, a secondary community mental-health service for the greater Rotterdam area in the Netherlands. General practitioners and specialists were asked to refer patients aged between 18 and 65 years whose physical symptoms, according to clinical judgment, could not be fully explained on the basis of a known medical condition. Patients were included if they signed the informed consent and if their UPS fulfilled the DSM-IV criteria for an undifferentiated somatoform disorder or a chronic pain disorder.

We chose UPS classified with DSM-IV as 'undifferentiated somatoform disorder' or as 'chronic pain disorder', as these disorders were given clinical relevance by their high prevalence - in general practices, they are the most prevalent of all somatoform disorders [25] - and as they 
could be selected by valid and reliable instruments. 'Undifferentiated somatoform disorder' and 'chronic pain disorder' are non-overlapping disorders because of criterion $\mathrm{E}$ in the DSM-IV criteria for 'undifferentiated somatoform disorder, which states that the disorder can be assigned only if the symptoms are not better accounted for by another mental disorder such as another somatoform disorder.

To verify whether UPS fulfilled all DSM-IV criteria for either 'undifferentiated somatoform disorder' or 'chronic pain disorder', we used the Structured Clinical Interview for DSM-IV Axis I Disorders (SCID-I) [26], a semistructured validated and reliable interview for making the major DSM-IV Axis I diagnoses.

Patients were excluded if they did not provide informed consent, or if poor language skills or handicaps such as cognitive impairment prevented them from understanding the CBT group training.

\section{CBT group training}

The intervention, a CBT group training called 'Coping with the consequences of unexplained physical symptoms', is a weekly two-hour manual-based [27] training that is held over a 13-week period. It uses the following CBT techniques: psychoeducation, response prevention, pacing activity, graded activity, graded exercise, problem-solving, breathing and relaxation exercise, cognitive intervention using the Ellis' ABC worksheet, and relapse prevention. Its aim is to improve health-related quality of life. A more detailed description of this CBT has been published elsewhere [24,28].

\section{CBT outcome measurement}

In the randomized controlled trial, the primary outcome was the summary scales of the 36-item Medical Outcomes Study Short-Form General Health Survey (SF-36) [29]: Physical Component Summary' (PCS) and 'Mental Component Summary' (MCS). In the present study, the PCS was chosen as outcome measurement, because patients reported the quality of life in the physical domain as most burdensome. The group training significantly improved quality of life in the physical domain, and this positive effect was maintained during the entire one-year follow-up period [30].

The PCS summarizes functional health and well-being in the physical domain over the past four weeks. This summary is transformed into T-scores with a mean of 50 and standard deviation of 10. A higher summary score indicates a better quality of life. The CBT outcome score was the difference between the baseline PCS score and the following: post-treatment PCS scores (immediate outcome); three-month follow-up PCS scores (shortterm outcome); and one-year follow-up PCS scores (long-term outcome). A higher CBT outcome score indicates more improvement of quality of life in the physical domain.

\section{Predictors \\ Psychological symptoms}

Psychological symptoms were measured using the revised 90-item Symptom Checklist (SCL-90-R). This is a validated and reliable self-report questionnaire with 90 questions and five fixed-response alternatives (Likerttype format: Not at all; Somewhat; Moderately; Very much; Absolutely) for evaluating a broad range of psychological symptoms, including anxiety and depression, over the past week [31]. The responses are summed up in the 'Global severity index'. A higher score on this index indicates more severe psychological symptoms or a higher number of psychological symptoms.

\section{Personality-disorder characteristics}

Personality-disorder characteristics were measured using the Vragenlijst Kenmerken van Persoonlijkheid (VKP), a Dutch self-report questionnaire based on the International Personality Disorder Examination [32]. The VKP is a validated and reliable self-report questionnaire with 197 questions and three fixed-response alternatives (true; ?; false) for assessing the presence of DSM-IV axis II criteria of personality disorders over the past five years. 'Personality-disorder characteristics' were calculated by summing DSM-IV axis II criteria, to which was responded with "true". A higher sum score indicates a higher number of DSM-IV axis II criteria confirmed.

\section{Presence of DSM-IV axis I disorders in the past ('psychiatric history')}

The presence per patient of DSM-IV axis I disorders, both currently and over their lifetime, was measured using the Structured Clinical Interview for DSM-IV axis I disorders (SCID-I) [26]. This is a semi-structured validated interview for classifying the major DSM-IV axis I disorders. The presence of these disorders in the past ('psychiatric history') was calculated by summing disorders in lifetime that were not currently present, and splitting the sum score into two categories (no DSM-IV axis I in the past, 0; or one or more DSM-IV axis I disorders in the past that were not currently present, 1).

\section{Health-related quality of life in the mental domain ('mental component summary')}

Health-related quality of life in the mental domain was measured using the 'Mental Component Summary' (MCS) of the SF-36 [29]. The MCS summarizes functional health and well-being in the mental domain over the past four weeks. This summary is transformed into T-scores with a mean of 50 and standard deviation of 
10. A higher MCS-score indicates a better health-related quality of life in the mental domain.

\section{Control variables}

Pretreatment PCS scores, age, gender, marital status and employment status were used as control variables.

\section{Statistical analyses \\ Required sample size}

The randomized controlled trial on the effectiveness of the CBT group training resulted in a group of 162 patients. To verify whether this fixed number of patients was also sufficient for the present study, we applied a power analysis to calculate the sample size required for the present study [33,34].

For this power analysis, the anticipated effect size of the set predictors was set at $\mathrm{f}^{2}=0.15$ [35]. We decided that the set should at least have this medium effect, because the predictors would exclude patients from treatment that had an exceptionally small risk of adverse events [36], and, also, because the selection and allocation assessment needed for this exclusion would raise costs. The desired statistical power level was set at 0.80 and the alpha at 0.05 ; both by convention [35]. The number of predictors was four, while the number of control variables was five. The predictors were selected on the basis of assumptions practiced in clinical practice. The control variables were chosen on the basis of findings of other studies that indicated the potential relevance of these variables for CBT outcome. By selecting predictors used in clinical practice and by choosing control variables indicated by studies as potentially relevant, we reduced the number of predictors and control variables, and prevented 'fishing'.

A power analysis with these parameters led to a minimum required sample size of 113 patients $[37,38]$. Adjusted for a dropout of 30 percent, this resulted in a total sample size of 161. The total sample size of 162 in the randomized controlled trial was thus sufficient for the hierarchical multiple regression analyses of the present study.

\section{Analyses}

The statistical analyses concern drop-out and prediction. Drop-out analyses explored whether the patients who dropped out differed at baseline from study completers (patients who could be followed over a year). This was analyzed using two-tailed t-tests for independent samples for the continuous variables, two-tailed MannWhitney U-tests for the ordinal variables, and chi-square tests for the categorical variables.

The prediction analyses included a preliminary exploration of the relationships between the individual predictors and CBT outcomes, and a full exploration of the predictive power of the predictor set while controlling for pre-treatment score of the outcome measure and socio-demographic variables. For the preliminary exploration, a correlation matrix was composed. For the full exploration, hierarchical multiple regression analyses were used. In the first step of these regression analyses, pretreatment score on the outcome measure and sociodemographic variables were simultaneously entered as a block to statistically control for their impact on outcome. In the second step of these regression analyses, the predictors were simultaneously entered as a block to evaluate their impact as a set and as individual predictors on outcome. Since predictors have clinical relevance only if they are stable over time, these analyses were conducted for immediate, short-term and long-term CBT outcomes.

Five checks were used to verify whether the assumptions of hierarchical multiple regression analysis had been met and how accurate the resulting model was $[33,39]$. The first check used was Cook's distance to explore whether the model was highly influenced by a small number of cases. The second check used was tolerance to confirm non-multicollinearity. The third check used was the Durbin-Watson statistics to confirm the independency of errors. The fourth check used was residual plots to explore for linearity and homoscedasticity. The fifth check used was the Shapiro-Wilk test to confirm the normality of standardized residuals.

\section{Results}

\section{Patients}

Figure 1 shows the flow chart of patients through the study. The study started with 162 patients, 59 of whom dropped out.

The 59 patients who had dropped out of the study did not differ from the study completers with regard to their available scores for CBT outcome, control variables, and predictors (see Table 1), with the exception of a difference in the 'age' control variable. Patients who had dropped out were significantly younger $(M=42.4$, $\mathrm{SD}=11.1, \mathrm{p}=.02)$ than the study completers $(\mathrm{M}=46.7$, $\mathrm{SD}=10.8)$.

With regard to the clinical characteristics shown in Table 2, no significant differences were found between the patients who had dropped out and the study completers.

\section{Correlations between CBT outcomes, control variables, and predictors}

Table 3 shows the correlation matrix between the CBT outcomes, the control variables, and predictors. With regard to the control variables, the only control variable that predicted outcome consistently over time was the pretreatment PCS score. A lower pretreatment PCS score was associated with a better CBT outcome. The 


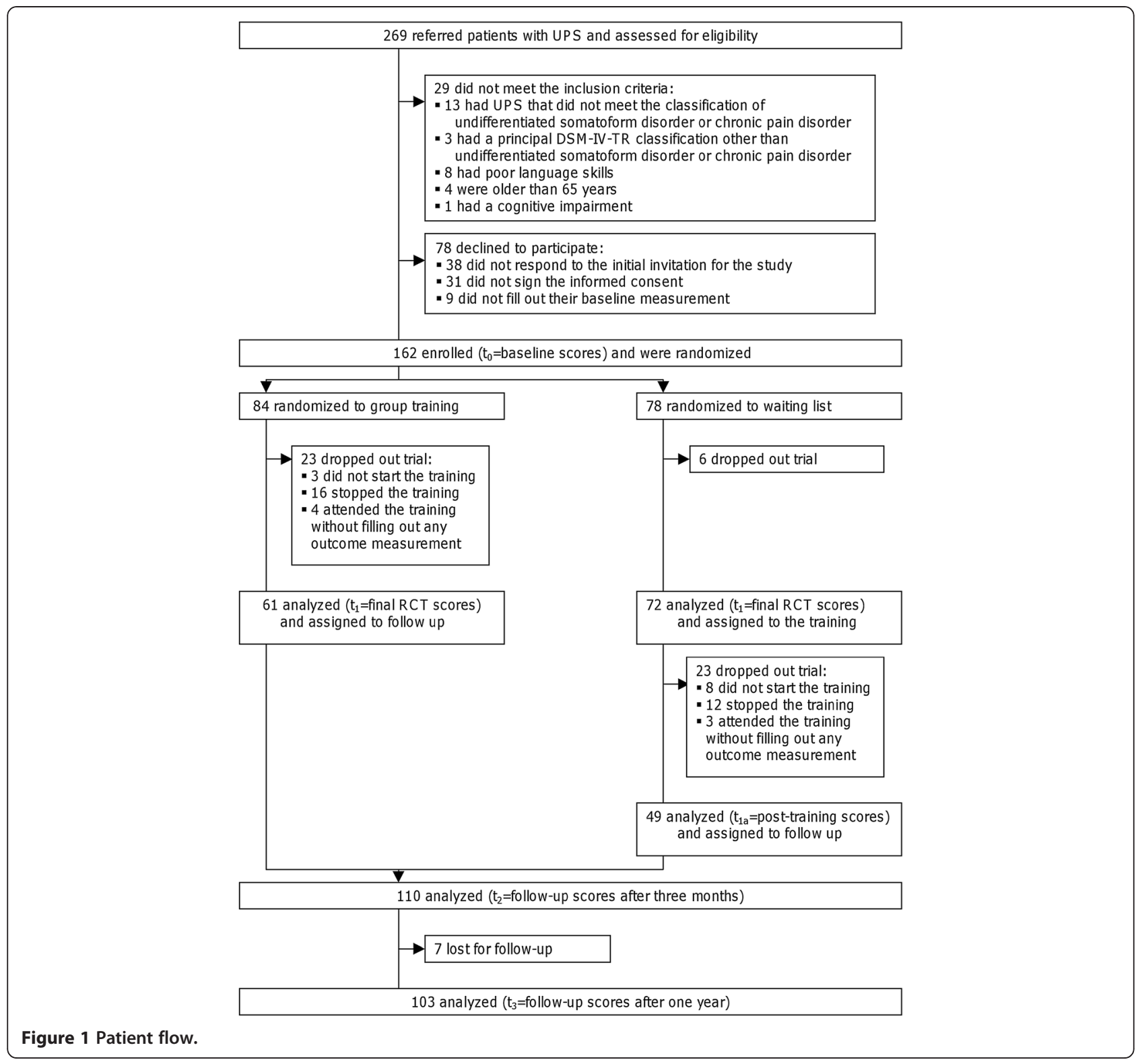

pretreatment PCS scores explained five to nine per cent of the variance in CBT outcome. With regard to the predictors, no predictor predicted outcome consistently over time. The correlations with CBT outcomes were rather low according to Cohen's guidelines [35]. Only the pretreatment MCS scores were significantly correlated with CBT short-term outcome. A higher pretreatment MCS score was associated with a better CBT short-term outcome. These pretreatment MCS scores explained six percent of the variance in the short-term CBT outcome.

\section{Prediction of immediate, short-term and long-term CBT outcome}

Table 4 shows the hierarchical multiple regression models for predicting CBT outcome. The complete model was able to predict immediate CBT outcome $(\mathrm{F}(9,92)=2.12$, $\mathrm{p}=.04)$ and short-term CBT outcome $(\mathrm{F}(9,95)=2.85, \mathrm{p}=.005)$; but not long-term CBT outcome $(\mathrm{F}(9,88)=1.81, \mathrm{p}=.08)$. When the effects of pretreatment outcome scores and socio-demographic variables were statistically controlled, the predictor set was only able to predict short-term CBT outcome $(\mathrm{F}(4,95)=4.41, \mathrm{p}=.003)$; but not immediate CBT outcome $(\mathrm{F}(4,92)=0.17, \mathrm{p}=.17)$ and long-term $\mathrm{CBT}$ outcome $(\mathrm{F}(4,88)=1.54, \mathrm{p}=.20)$. The resulting explained variance in CBT outcome training was $6 \%$ at the end of CBT, $15 \%$ at three-month follow-up, and 6\% at one-year follow-up. For short-term CBT outcome, better outcome was predicted by more psychological symptoms, fewer personality-disorder characteristics, the presence of a psychiatric history, and a better quality of life in the mental domain. There were no 
Table 1 Characteristics of CBT outcomes, control variables, and predictors

\begin{tabular}{|c|c|c|c|}
\hline CBT outcome & $\mathrm{n}$ & & \\
\hline Immediate CBT outcome, mean (SD) & 102 & 4.49 & $(7.59)$ \\
\hline Short-term CBT outcome, mean (SD) & 105 & 4.68 & $(6.79)$ \\
\hline Long-term CBT outcome, mean (SD) & 98 & 5.03 & $(7.55)$ \\
\hline Control variables & $\mathrm{n}$ & & \\
\hline $\begin{array}{l}\text { Physical Component Summary - PCS, } \\
\text { mean (SD) }\end{array}$ & 158 & 29.20 & $(8.97)$ \\
\hline Age in years, mean (SD) & 162 & 45.15 & $(11.05)$ \\
\hline Gender, n (\%) & 162 & & \\
\hline female & & 131 & $(81 \%)$ \\
\hline male & & 31 & $(19 \%)$ \\
\hline Marital status, n (\%) & 162 & & \\
\hline married/living with a partner & & 110 & $(68 \%)$ \\
\hline unmarried/divorced/widowed & & 52 & $(32 \%)$ \\
\hline Employment, $\mathrm{n}(\%)$ & 162 & & \\
\hline having employment & & 57 & $(35 \%)$ \\
\hline having no employment & & 105 & $(65 \%)$ \\
\hline Predictors & $\mathrm{n}$ & & \\
\hline Global severity index, mean (SD) & 161 & 165.36 & $(50.28)$ \\
\hline $\begin{array}{l}\text { Personality-disorder characteristics, } \\
\text { mean (SD) }\end{array}$ & 160 & 15.07 & $(12.96)$ \\
\hline Psychiatric history, n (\%) & 162 & & \\
\hline presence of a psychiatric history & & 68 & $(42 \%)$ \\
\hline absence of a psychiatric history & & 94 & $\overline{(58 \%)}$ \\
\hline $\begin{array}{l}\text { Mental Component Summary - MCS, } \\
\text { mean (SD) }\end{array}$ & 158 & 45.15 & $(11.89)$ \\
\hline
\end{tabular}

indications that the models were highly influenced by a small number of cases or by violating the assumptions of hierarchical multiple regressions analysis.

\section{Discussion}

\section{Principal findings}

We explored whether psychological symptoms, personality-disorder characteristics, psychiatric history, and health-related quality of life in the mental domain assessed at baseline predicted CBT outcome at the end of CBT (immediate outcome), three months after CBT (short-term outcome) and one year after CBT (longterm outcome), all after control for pretreatment scores on the outcome measure and for socio-demographic variables. We found that these predictors in combination with the control variables significantly predicted the immediate and short-term outcome of CBT, but not the long-term outcome.

The predictor set alone was significantly associated only with short-term CBT outcome. At this time-point, all predictors were significant. Psychological symptoms had the strongest association with short-term outcome followed by - in descending order of strength - health-
Table 2 Clinical characteristics

\begin{tabular}{|c|c|}
\hline Clinical characteristics & $\mathrm{n}=162$ \\
\hline Duration of UPS in years, median (interquartile range) & $9(3-16)$ \\
\hline \multicolumn{2}{|l|}{ Classification of UPS by SCID-I } \\
\hline undifferentiated somatoform disorder & 63 \\
\hline chronic pain disorder & 99 \\
\hline \multicolumn{2}{|l|}{ Number of comorbid DSM-IV Axis I disorders } \\
\hline no comorbid DSM-IV Axis I disorder & 95 \\
\hline one comorbid DSM-IV Axis I disorder & 43 \\
\hline two comorbid DSM-IV Axis I disorders & 17 \\
\hline three comorbid DSM-IVAxis I disorders & 4 \\
\hline four or more comorbid DSM-IVAxis I disorders & 3 \\
\hline
\end{tabular}

\section{Classification of comorbid DSM-IV Axis I disorder}

\begin{tabular}{lr}
\hline mood disorder (in past; in lifetime) & $24(46 ; 70)$ \\
\hline anxiety disorder (in past; in lifetime) & $47(30 ; 77)$ \\
\hline substance-related disorder (in past; in lifetime) & $1(17 ; 18)$ \\
\hline eating disorder (in past; in lifetime) & $1(5 ; 6)$ \\
\hline psychotic disorder (in past; in lifetime) & $0(1 ; 1)$ \\
\hline other somatoform disorder (in lifetime) & $26(26)$ \\
\hline adjustment disorder (in lifetime) & $4(4)$ \\
\hline other disorder (in past; in lifetime) & $1(0 ; 1)$ \\
\hline Number of comorbid DSM-IV Axis II disorders & 113 \\
\hline no comorbid DSM-IV Axis II disorder & 27 \\
\hline one comorbid DSM-IV Axis II disorder & 10 \\
\hline two comorbid DSM-IV Axis II disorders & 10 \\
\hline three or more comorbid DSM-IV Axis II disorders
\end{tabular}

\section{Classification of comorbid DSM-IV Axis II disorder}

\begin{tabular}{lr}
\hline paranoid personality disorder & 18 \\
\hline schizoid personality disorder & 5 \\
\hline schizotypal personality disorder & 2 \\
\hline anti-social personality disorder & 1 \\
\hline borderline personality disorder & 7 \\
\hline histrionic personality disorder & 2 \\
\hline narcissistic personality disorder & 2 \\
\hline avoidant personality disorder & 29 \\
\hline dependent personality disorder & 4 \\
\hline obsessive compulsive personality disorder & 24
\end{tabular}

Psychiatric history (number of past DSM-IV axis I disorders)

\begin{tabular}{lr}
\hline no past DSM-IV Axis I disorder & 94 \\
\hline one past DSM-IV Axis I disorder & 46 \\
\hline two past DSM-IV Axis I disorders & 17 \\
\hline three past DSM-IVAxis I disorders & 3 \\
\hline four or more past DSM-IVAxis I disorders & 2 \\
\hline Referrer & 82 \\
\hline primary medical service & 51 \\
\hline secondary medical service & 29 \\
\hline secondary mental service
\end{tabular}


Table 3 Correlation matrix with CBT outcomes, control variables and predictors

\begin{tabular}{|c|c|c|c|}
\hline & \multicolumn{3}{|c|}{ CBT outcome } \\
\hline & Immediate & Short-term & Long-term \\
\hline \multicolumn{4}{|l|}{ CBT outcome } \\
\hline Immediate CBT outcome & 1.00 & & \\
\hline Short-term CBT outcome & $.60^{* * *}$ & 1.00 & \\
\hline Long-term CBT outcome & $.58^{* * *}$ & $.58^{* * *}$ & 1.00 \\
\hline \multicolumn{4}{|l|}{ Control variables } \\
\hline $\begin{array}{l}\text { Physical Component } \\
\text { Summary (SF-36: PCS) }\end{array}$ & $-.30^{* *}$ & $-.24^{*}$ & $-.22^{*}$ \\
\hline Age & -.03 & .05 & -.15 \\
\hline Gender & -.02 & -.01 & .04 \\
\hline Marital status & .07 & -.02 & .06 \\
\hline Employment & -.07 & -.08 & .07 \\
\hline \multicolumn{4}{|l|}{ Predictors } \\
\hline $\begin{array}{l}\text { Global severity index } \\
\text { (SCL-90-R) }\end{array}$ & .11 & .01 & .10 \\
\hline $\begin{array}{l}\text { Personality-disorder } \\
\text { characteristics (VKP) }\end{array}$ & -.04 & -.17 & -.11 \\
\hline Psychiatric history (SCID-I) & -.01 & .13 & -.01 \\
\hline $\begin{array}{l}\text { Mental Component } \\
\text { Summary (SF-36: MCS) }\end{array}$ & .19 & $.25^{* *}$ & .11 \\
\hline
\end{tabular}

related quality of life in the mental domain, personalitydisorder characteristics, and psychiatric history. Psychological symptoms, health-related quality of life in the mental domain, and psychiatric history were positively associated with short-term outcome, meaning that a better outcome was expected if the number of psychological symptoms had been higher at baseline, if quality of life had been better at baseline, and if a psychiatric history had been present at baseline. Personality-disorder characteristics were negatively associated with short-term outcome, meaning a better outcome was expected if the number of personality-disorder characteristics had been lower at baseline.

As the predictor set did not significantly predict outcome at all three time points, its effects were not stable over time. This instability makes it unsuitable for selection and allocation of patients to CBT.

Our principal findings in relation to the existing literature The finding that effects of predictors were not stable over time was consistent with the findings of other studies [7-21] that have investigated the association between psychiatric comorbidity and outcome, and showed no stability of predictors between studies or over time within studies. However, unlike these studies $[10,12,15]$, our own study controlled statistically for the effects of pretreatment score on the outcome measure and sociodemographic variables. Even under these conditions, predictors still did not consistently predict which patients benefited from CBT and which did not.

The possible reasons for the inconsistent findings over studies on predictor effects might be that the study groups were too small or the group of patients with UPS studied was too heterogeneous. Other reasons might be that the sets of predictors in the studies were wrongly measured and/or chosen. Predicting CBT outcome might be more complex, and may require a larger set of variables than the sets of predictors which were investigated in the studies. For instance, it may require a good match between trainer and trainees, a supportive but not over-protective partner, no deaths nearby, no moving house, and no termination of employment. It has been estimated that factors in client-therapist relationship account for $30 \%$ of treatment outcome, and factors outside CBT for another 40\% [40].

\section{Strengths and limitations in the study}

The strength of the present study was that the impact of a predictor set on the primary outcome measure was explored at three time points over one year after CBT [2]. As most other studies were designed to predict treatment outcome at only one time point after CBT $[8,13-15]$, they did not explore the stability of the predictor effect over time. They also used more than one outcome measure without indicating the primary outcome measure $[8,12,15,18]$. By this, other studies did not explore the stability of predictor effects over time on the outcome measure that was preliminary chosen as the most important outcome of CBT.

A limitation of the study was that personality-disorder characteristics were measured using a self-report questionnaire. Although many patients met the DSM-IV axis II criteria for the classification of a specific personalitydisorder subtype, only two met the general criteria applying to all personality disorders. Patients seemed to view any maladaptive thoughts, feelings and behavior associated with personal and social disruption as a specific reaction to a situation rather than a pervasive and stable pattern across many situations. If these reactions were indeed determined by a specific situation, our classification of their personality disorders would have been incorrect. However, a high number of personality disorders was to be expected: our patients had had their UPS for an average of nine years, and the prevalence of personality disorders in such patients is four times higher than in the healthy population [41]. The total number of DSM-IV axis II criteria confirmed in our study (mean=15.07 and standard deviation $=12.96)$ was significantly larger than the mean in the 'normal population' reference group (mean=12.54 and standard deviation=9.79), and significantly less than the one in the 'psychiatric patients' reference group (mean=25.37 and 
Table 4 Hierarchical multiple regression models for predicting CBT outcome

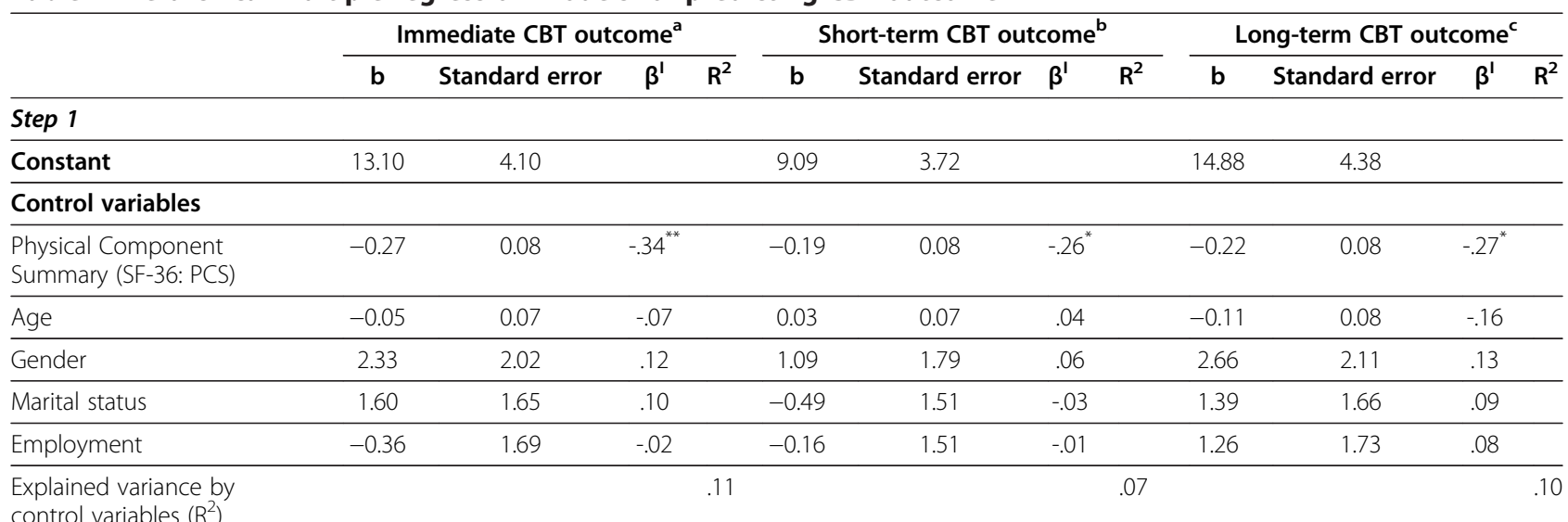

Step 2

\begin{tabular}{|c|c|c|c|c|c|c|c|c|c|c|}
\hline Constant & -10.06 & 10.22 & & -12.36 & 8.24 & & 0.87 & 10.57 & & \\
\hline \multicolumn{11}{|l|}{ Control variables } \\
\hline $\begin{array}{l}\text { Physical Component } \\
\text { Summary (SF-36: PCS) }\end{array}$ & -0.16 & 0.09 & -.20 & -0.10 & 0.08 & -.13 & -0.15 & 0.09 & -.19 & \\
\hline Age & -0.01 & 0.07 & -.02 & 0.04 & 0.06 & .06 & -0.10 & 0.08 & -.14 & \\
\hline Gender & 1.05 & 2.20 & .05 & 0.92 & 1.89 & .05 & 1.51 & 2.32 & .07 & \\
\hline Marital status & 1.85 & 1.65 & .11 & -0.42 & 1.42 & -.03 & 1.25 & 1.66 & .08 & \\
\hline Employment & -0.53 & 1.68 & -.03 & -0.71 & 1.43 & -.05 & 1.06 & 1.73 & .06 & \\
\hline \multicolumn{11}{|l|}{ Predictors } \\
\hline Global severity index (SCL-90) & 0.06 & 0.03 & $.36^{*}$ & 0.06 & 0.02 & $.41^{* *}$ & 0.06 & 0.03 & .33 & \\
\hline $\begin{array}{l}\text { Personality-disorder } \\
\text { characteristics (VKP) }\end{array}$ & -0.08 & 0.09 & -.11 & -0.19 & 0.07 & $-.32^{*}$ & -0.18 & 0.09 & -.28 & \\
\hline Psychiatric history (SCID) & 0.72 & 1.50 & .05 & 2.79 & 1.27 & $.20^{*}$ & 1.12 & 1.52 & .07 & \\
\hline $\begin{array}{l}\text { Mental Component } \\
\text { Summary (SF-36: MCS) }\end{array}$ & 0.20 & 0.09 & $.30^{*}$ & 0.21 & 0.07 & $.36^{* *}$ & 0.10 & 0.09 & .15 & \\
\hline $\begin{array}{l}\text { Explained variance by } \\
\text { predictors }\left(\Delta R^{2}\right)\end{array}$ & & & \multicolumn{2}{|c|}{.06} & & \multicolumn{2}{|c|}{$.15^{* *}$} & \multicolumn{3}{|r|}{.06} \\
\hline
\end{tabular}

standard deviation $=13.55$ ) [32]. The validity problem caused by failure to meet the general criteria applicable to all personality disorders might be partially solved by using structured interviews. Although this might provide a more objective perspective, it still depends on information communicated by patients and also on patients' views of their own thoughts, feelings and behavior.

\section{Clinical and policy implications}

In routine practice assessments, patients with UPS are selected and allocated to different kinds of treatment on the basis of psychological symptoms, personalitydisorder characteristics, psychiatric history, and healthrelated quality of life. As the prevalence of comorbid mood, anxiety [42], and personality disorders [41] is high in this patient group, patients are often redirected from treatment for UPS to treatment for mental health problems, which is usually provided by the mental health services. However, these predictors did not consistently predict CBT outcome, neither in our study nor in our review of other studies, and as a substantial number of patients communicates in physical and not mental terms [43] and refuses to be referred to the mental health services $[5,44]$, this practice does not seem to be appropriate.

\section{Conclusions}

As psychological symptoms, personality-disorder characteristics, psychiatric history, and health-related quality of life in the mental domain assessed at baseline did not seem to predict CBT outcome consistently over time, the need for selection and allocation of patients on the 
basis of these variables to CBT is doubtful. In our study, if patients had been excluded from CBT on the basis of these variables, they would have been deprived unnecessarily of effective group training.

\section{Abbreviations}

CBT: Cognitive behavioral therapy; MCS: Mental component summary of the SF-36; PCS: Physical component summary of SF-36; SCID-I: Structured clinical interview for DSM-IV axis I disorders; SCL-90-R: 90-Item symptom checklist revised; SF-36: 36-item medical outcomes study short-form general health survey; UPS: Unexplained physical symptoms; VKP: Vragenlijst kenmerken van persoonlijkheid, a Dutch self-report questionnaire based on the international personality disorder examination.

\section{Competing interests}

All authors declare that they have no competing interests by publishing this report.

\section{Authors' contributions}

LNLZ developed the original idea of the study, implemented the study, conducted the analyses and drafted the manuscript. All authors read and corrected draft versions. All authors approved the final version of this manuscript.

\section{Authors' information}

LNLZ is clinical psychologist, psychotherapist and cognitive behaviora therapist. YRvR is clinical psychologist, psychotherapist and cognitive behavioral therapist. CGK is psychiatrist and psychoanalytist. RT is assistant professor and statistician. AvtS is assistant professor and psychotherapist. JJVB is professor of health-related quality of life, ad interim chair of the department Medical Psychology and Psychotherapy of Erasmus Medical Center in Rotterdam, and managing director of the Viersprong Institute for studies on Personality Disorders (VISPD) of the Viersprong' in Halsteren, the Netherlands.

\section{Acknowledgements}

The institutions concerned did not receive third-party funds for this study.

\section{Author details}

${ }^{1}$ Department of Medical Psychology and Psychotherapy, Erasmus Medical Center, PO Box 2040, Rotterdam 3000 CA, the Netherlands. ${ }^{2}$ Department of Medical Psychology, Academic Medical Center, PO Box 22660, Amsterdam 1100 DD, the Netherlands. ${ }^{3}$ Department of Anesthesiology, Academic Medical Center, PO Box 22660, Amsterdam 1100 DD, the Netherlands. ${ }^{4}$ Department of Psychiatry, Leiden University Medical Centre, PO Box 9600 , Leiden 2300 RC, the Netherlands. ${ }^{5}$ Riagg Rijnmond, Stationsplein 2, Schiedam $3112 \mathrm{HJ}$, the Netherlands.

Received: 7 February 2012 Accepted: 2 October 2012

Published: 8 October 2012

\section{References}

1. Kroenke K: Efficacy of treatment for somatoform disorders: a review of randomized controlled trials. Psychosom Med 2007, 69(9):881-888.

2. Nezu AM, Nezu CM, Lombardo ER: Cognitive-behavior therapy for medically unexplained symptoms: a critical review of the treatment literature. Behav Ther 2001, 32(3):537-583.

3. Sumathipala $A$ : What is the evidence for the efficacy of treatments for somatoform disorders? A critical review of previous intervention studies. Psychosom Med 2007, 69(9):889-900.

4. Allen LA, Woolfolk RL, Escobar Jl, Gara MA, Hamer RM: Cognitive-behavioral therapy for somatization disorder: a randomized controlled trial. Arch Intern Med 2006, 166:1512-1518.

5. Allen LA, Woolfolk RL: Cognitive behavioral therapy for somatoform disorders. Psychiatr Clin North Am 2010, 33:579-593.

6. Escobar Jl, Gara MA, Diaz-Martinez AM, Interian A, Warman M, Allen LA, Woolfolk RL, Jahn E, Rodgers D: Effectiveness of a time-limited cognitive behavior therapy-type intervention among primary care patients with medically unexplained symptoms. Ann Fam Med 2007, 5(4):328-335.
7. Greeven A, Van Balkom AJ, Van der Leeden R, Merkelbach JW, Van den Heuvel OA, Spinhoven P: Cognitive behavioral therapy versus paroxetine in the treatment of hypochondriasis: an 18-month naturalistic follow-up. $J$ Behav Ther Exp Psychiatry 2009, 40(3):487-496.

8. Leibbrand R, Hiller W, Fichter MM: Effect of comorbid anxiety, depressive, and personality disorders on treatment outcome of somatoform disorders. Compr Psychiatry 1999, 40(3):203-209.

9. Rief W, Hiller W, Geissner E, Fichter MM: A two-year follow-up study of patients with somatoform disorders. Psychosomatics 1995, 36(4):376-386.

10. Buwalda FM, Bouman TK: Predicting the effect of psychoeducational group treatment for hypochondriasis. Clin Psychol Psychother 2008, 15:396-403.

11. Kellner R: Prognosis of treated hypochondriasis. Acta Psychiatr Scand 1983, 67:69-79.

12. Blanchard EB, Lackner JM, Gusmano R, Gudleski GD, Sanders K, Keefer L, Krasner S: Prediction of treatment outcome among patients with irritable bowel syndrome treated with group cognitive therapy. Behav Pharmacol 2006, 44:317-337.

13. Shorter E, Abbey SE, Gillies LA, Singh M, Lipowski ZJ: Inpatient treatment of persistent somatization. Psychosomatics 1992, 33(3):295-301.

14. Nakao M, Fricchione G, Myers P, Zuttermeister PC, Baim M, Mandle $C L$, Medich C, Wells-Federman CL, Arcari PM, Ennis M, et al: Anxiety is a good indicator for somatic symptom reduction through behavioral medicine intervention in a mind/body medicine clinic. Psychother Psychosom 2001, 70:50-57.

15. Bleichhardt G, Timmer B, Rief W: Prädiktoren für den direkten und längerfristigen therapieerfolg bei patienten mit somatoformen störungen nach verhaltenstherapeutischer behandlung. Z Klin Psychol Psychiatr Psychother 2005, 53(1):40-58.

16. Leibbrand R, Hiller W, Fichter MM: Influence of personality disorders on therapy outcome in somatoform disorders at 2-year follow-up. J Nerv Ment Dis 1999, 187(8):509-512.

17. Hiller W, Leibbrand R, Rief W, Fichter MM: Predictors of course and outcome in hypochondriasis after cognitive-behavioural treatment. Psychother Psychosom 2002, 71:318-325.

18. Prins J, Bleijenberg G, Rouweler EK, Van der Meer J: Effect of psychiatric disorders on outcome of cognitive-behavioural therapy for chronic fatigue syndrome. Br J Psychiatry 2005, 187:184-185.

19. Deale A, Chalder T, Marks I, Wessely S: Cognitive behavior therapy for chronic fatigue syndrome: a randomized controlled trial. Am J Psychiatry 1997, 154:408-414

20. Michaelson $P$, Sjölander $P$, Johansson $H$ : Factors predicting pain reduction in chronic back and neck pain after multimodal treatment. Clin J Pain 2004, 20(6):447-454.

21. Bonner D, Ron M, Chalder T, Butler S, Wessely S: Chronic fatigue syndrome: a follow up study. J Neurol Neurosurg Psychiatry 1994, 57:617-621.

22. Zonneveld LNL, Van Rood YR, Timman R, Kooiman CG, Vant Spijker A, Busschbach JJV: Effective group training for patients with unexplained physical symptoms: a randomized controlled trial with a nonrandomized one-year follow-up. PLoS One 2012, 7(8):e42629.

23. Group training for patients with unexplained physical symptoms http://www.trialregister.nl/trialreg/admin/rctview.asp?TC=1609.

24. Zonneveld LNL, Van't Spijker A, Passchier J, Van Busschbach JJ, Duivenvoorden $\mathrm{HJ}$ : he effectiveness of a training for patients with unexplained physical symptoms: protocol of a cognitive behavioral group training and randomized controlled trial. BMC Publ Health 2009, 9:251.

25. De Waal MWM, Arnold IA, Eekhof JAH, Van Hemert AM: Somatoform disorders in general practice: prevalence, functional impairment and comorbidity with anxiety and depressive disorders. Br J Psychiatry 2004, 184(6):470-476.

26. First MB, Spitzer RL, Gibbon M, Williams JBW: Structured clinical interview for DSM-IV axis I disorders. Amsterdam: Harcourt Test Publishers; 1999.

27. Zonneveld LNL: Draaiboek 'Omgaan met de gevolgen van onverklaarde lichamelijke klachten'. Vlaardingen/Rotterdam: Riagg Rijnmond/Erasmus MC Department of Medical Psychology and Psychotherapy; 2005.

28. Zonneveld LNL, Duivenvoorden HJ, Passchier J, Van't Spijker A: Tailoring a cognitive behavioural model for unexplained physical symptoms to patientcs perspective: a bottom-up approach. Clin Psychol Psychother 2010, 17(6):528-535 
29. Ware JE, Snow KK, Kosinski M, Gandek B: SF-36 health survey: manual and interpretation guide. Boston, MA: New England Medical Center, The Health Institute; 1993.

30. Zonneveld LNL, Van Rood YR, Timman R, Kooiman CG, Vant Spijker A, Busschbach JJV: Effective group training for patients with unexplained physical symptoms: a randomized controlled trial with a nonrandomized one-year follow-up. PLoS One 2012, 7(8):e42629.

31. Arrindell WA, Ettema JHM: SCL-90/symptom checklist: handleiding bij een multidimensionele psychopathologie-indicator. Lisse: Swets Test Publishers; 2003.

32. Duijsens IJ, Haringsma R, Eurelings-Bontekoe EHM: V.K.P. handleiding. Leiderdorp: Datec; 2002.

33. Field A: Regression, Discovering statistics using SPSS. 3rd edition. London: Sage; 2009:197-263.

34. Miles JNV, Shevlin M: Issues in regression analysis, Applying regression and correlation: a guide for students and researchers. London: Sage; 2001:119-121.

35. Cohen J: Statistical power analysis for the behavioral sciences. Hillsdale, New Jersey: Lawrence Erlbaum; 1988

36. Heins MJ, Knoop H, Prins JB, Stulemeijer M, Van der Meer JWM, Bleijenberg G: Possible detrimental effects of cognitive behaviour therapy for chronic fatique syndrome. Psychother Psychosom 2010, 79:249-256.

37. A-priori sample size calculator for multiple regression: online software. http://www.danielsoper.com/statcalc3.

38. Green SB: How many subjects does it take to do a regression-analysis. Multivar Behav Res 1991, 26(3):499-510.

39. Pallant J: SPSS survival manual: a step by step guide to data analysis using SPSS for Windows (Version 12). 2nd edition. Maidenhead Berkshire: Open University Press; 2005.

40. Lambert MJ, Barley DE: Research summary on the therapeutic relationship and psychotherapy outcome. Psychotherapy: theory, research, practice training 2001, 38(4):357-361.

41. Nater UM, Jones JF, Lin J-MS, Maloney E, Reeves WC, Heim C: Personality features and personality disorders in chronic fatigue syndrome: a population-based study. Psychother Psychosom 2010, 79:312-318.

42. Henningsen P, Zimmermann T, Sattel H: Medically unexplained physical symptoms, anxiety, and depression: a meta-analytic review. Psychosom Med 2003, 65:528-533.

43. Peters S, Rogers A, Salmon P, Gask L, Dowrick C, Towey M, Clifford R, Morriss R: What do patients choose to tell their doctors? Qualitative analysis of potential barriers to reattributing medically unexplained symptoms. $J$ Gen Intern Med 2008, 24(4):443-449.

44. Raine R, Haines A, Sensky T, Hutchings A, Larkin K, Black N: Systematic review of mental health interventions for patients with common somatic symptoms: can research evidence from secondary care be extrapolated to primary care? Br Med J 2002, 325:1082-1092.

doi:10.1186/1471-2458-12-848

Cite this article as: Zonneveld et al:: Predicting the outcome of a cognitive-behavioral group training for patients with unexplained physical symptoms: a one-year follow-up study. BMC Public Health 2012 12:848

\section{Submit your next manuscript to BioMed Central and take full advantage of:}

- Convenient online submission

- Thorough peer review

- No space constraints or color figure charges

- Immediate publication on acceptance

- Inclusion in PubMed, CAS, Scopus and Google Scholar

- Research which is freely available for redistribution 